\title{
Dementia, awareness and depression
}

\author{
Citation for published version (APA):
}

Verhey, F. R. J., Rozendaal, N., Ponds, R. W. H. M., \& Jolles, J. (1993). Dementia, awareness and depression. International Journal of Geriatric Psychiatry, 8(10), 851-856.

https://doi.org/10.1002/gps.930081008

Document status and date:

Published: 01/01/1993

DOI:

10.1002/gps.930081008

Document Version:

Publisher's PDF, also known as Version of record

\section{Please check the document version of this publication:}

- A submitted manuscript is the version of the article upon submission and before peer-review. There can be important differences between the submitted version and the official published version of record.

People interested in the research are advised to contact the author for the final version of the publication, or visit the DOI to the publisher's website.

- The final author version and the galley proof are versions of the publication after peer review.

- The final published version features the final layout of the paper including the volume, issue and page numbers.

Link to publication

\footnotetext{
General rights rights.

- You may freely distribute the URL identifying the publication in the public portal. please follow below link for the End User Agreement:

www.umlib.nl/taverne-license

Take down policy

If you believe that this document breaches copyright please contact us at:

repository@maastrichtuniversity.nl

providing details and we will investigate your claim.
}

Copyright and moral rights for the publications made accessible in the public portal are retained by the authors and/or other copyright owners and it is a condition of accessing publications that users recognise and abide by the legal requirements associated with these

- Users may download and print one copy of any publication from the public portal for the purpose of private study or research.

- You may not further distribute the material or use it for any profit-making activity or commercial gain

If the publication is distributed under the terms of Article $25 \mathrm{fa}$ of the Dutch Copyright Act, indicated by the "Taverne" license above, 


\title{
DEMENTIA, AWARENESS AND DEPRESSION
}

\author{
FRANS R.J. VERHEY,* NICO ROZENDAAL, $\dagger$ RUDOLF W.H.M. PONDS $\ddagger$ AND JELLEMER JOLLES§ \\ *Neuropsychiatrist, $\uparrow$ Research Assistant, $\ddagger$ Neuropsychologist, $\$$ Neuropsychologist/Neurochemist, Dept of Psychiatry, \\ University Hospital of Maastricht, and Dept of Neuropsychology and Psychobiology, University of Limburg, The \\ Netherlands
}

\begin{abstract}
SUMMARY
We examined 170 outpatients, 103 with Alzheimer's disease, 43 with vascular dementia and 24 with various other causes, in order to investigate whether or not depressive symptoms were more likely to occur in dementia patients who had some degree of awareness of their cognitive deterioration. Awareness was rated on a four-point scale that assessed discrepancies between the patient's and the caregiver's history. The level of awareness was significantly related to the severity of dementia but not to depression or to the score on Hamilton's depression scale. However, the score from the item 'psychic anxiety' showed a weak but significant correlation with the level of awareness of one's deficits. It is concluded that intact awareness of deterioration was not clearly related to the development of depression or depressive symptoms in dementia.
\end{abstract}

KEY wORDS-Awareness, anosognosia, dementia, insight, depression, Alzheimer's disease, vascular dementia.

It is well established that symptoms of depression occur more frequently in patients with Alzheimer's disease $(\mathrm{AD})$ and other dementing disorders than in the normal elderly population (McAllister and Price, 1982; Lazarus et al., 1987; Wragg and Jeste, 1989; Fischer et al., 1990). Insight into the relationship between depression and dementia contributes to the understanding of the pathogenesis of the disorder and has important implications for the choice of therapeutic strategies. An overlap in the neuropathological and neurochemical substrate of depression and $\mathrm{AD}$, cerebrovascular disease and Parkinson's disease has been suggested as a biological explanation for the higher prevalence rate of depression in dementia (eg Zubenko and Moossy, 1988; Starkstein and Robinson, 1989; Zubenko et al., 1990; Cummings, 1992). In contrast, psychological mechanisms underlying the depressive symptoms of demented patients have received much less attention. In this respect, the phenomenon of awareness in dementia may be relevant. The terms unawareness of deficits, lack of insight and

Address for correspondence: F.R.J. Verhey, MD, Dept of Psychiatry, University Hospital of Maastricht, PO Box 5800, 6202 AZ Maastricht, The Netherlands, Tel: (0)43-877443. Fax: (0)43-875444.

Part of this paper was presented at the 3rd International Conference on Alzheimer's Disease, Abano Terme, Italy, July 1992; see also Neurobiology and Aging, 1992, S1, 4. anosognosia (which are used interchangeably in this article, in accordance with the literature) refer to a lack of knowledge or recognition of one's deficits (McGlynn and Schachter, 1989). The few publications that exist on anosognosia in dementia report a general pattern of decreasing insight with increasing severity of the dementing process (Reisberg et al., 1985; McGlynn and Schachter, 1989; Feher et al., 1991). Depressive symptoms have also been reported to occur more frequently in mild dementia than in the more severe stages (Cummings et al., 1987; Fischer et al., 1990). Thus, depressed feelings in demented patients may be seen as an understandable reaction as a patient becomes aware of his or her loss of intellectual capacity and impending deterioration; as insight deteriorates with the progression of dementia, the patient may be less liable to suffer from depression (eg Wells, 1977; Verwoerdt, 1982; Hachinski, 1983).

The aim of this study was to ascertain whether or not depressive symptoms are indeed more likely to occur in demented patients who have some degree of awareness of their deficits than in those who lack this insight. We expected the outcome to show that patients who are relatively aware of their deficits are more likely to develop depression or, at least, depressive symptoms and that anosognosia may 'protect' against depressive symptoms in dementia. 


\section{PATIENTS AND METHODS}

The subjects were 170 outpatients with dementia who had been consecutively referred to the Maastricht Memory Clinic of the University Hospital of Maastricht (Verhey et al., 1993). Dementia was diagnosed according to the DSM-III-R criteria (American Psychiatric Association, 1987). Patients were diagnosed as possible or probable Alzheimer's disease (AD) based on the NINCDS criteria (McKhann et al., 1984). The diagnosis of vascular dementia (VD) was based on a score of 4 or more on Rosen's modified ischaemic score (IS) (Rosen et al., 1980). It should be noted that, in contrast to Hachinski's original IS, the modified IS does not include the items depression and retained personality. Other aetiologies were diagnosed according to regular criteria. The severity of dementia was assessed by the Global Deterioration Scale (GDS, Reisberg et al., 1982). In the assessment of depression in dementia, a distinction was made between the syndrome of depression and symptoms of depression. A diagnosis of a depressive syndrome was made according to the DSM-III-R criteria for major depressive episode without applying the organic exclusion (American Psychiatric Association, 1987). The Hamilton Depression Rating Scale of Depression (HRSD, 17-item version, Hamilton, 1960) was administered to obtain a measure of the severity of depression and as a checklist for depressive symptoms. The reliability of this clinician-rated scale has been demonstrated in demented patients (Gottlieb et al., 1988; Ott and Fogel, 1992).

\section{Assessment of awareness}

No generally accepted standardized assessment procedure to measure anosognosia or impaired awareness is available to date. For the purpose of this study, impaired awareness was defined, according to Schachter (1990), as the absence of knowledge or recognition of cognitive deficits. In analogy to others, the degree of awareness was assessed by comparing the patient's and the caregiver's history (see McGlynn and Schachter, 1989; Schachter, 1990). Awareness of deficits was rated on a four-point scale, ranging from 4 ('intact') to 1 ('absent'), using the guidelines shown in the Appendix. It was scored by the neuropsychiatrist who carried out the initial interview with the patient and his or her caregiver.

\section{Statistical analysis}

Because of the ordinal level of most of the data, non-parametric tests were used for the analysis of the dependent variables of awareness score, GDS score and depression score: rank-order correlation coefficient (Spearman) for correlations between variables, Wilcoxon's test (rank sums) for group differences, and Kruskal-Wallis rank ANOVA with covariates, which approximates a chi-square distribution (Siegel and Castellan, 1988). $t$-tests were used to examine differences in age between the groups. Probabilities greater than 0.05 were considered as non-significant. In the analysis of the HRSD subitems, a level of $p$ less than 0.002 was adopted according to a Bonferroni-type adjustment, to protect against spurious significance arising from multiple comparisons.

\section{RESULTS}

The study group consisted of 170 patients, 103 with $A D$ and 43 with VD and 24 with other causes (seven Parkinson's disease, four frontal lobe dementia, two normal pressure hydrocephalus, two alcoholrelated dementia, two Huntington's disease and seven miscellaneous causes). Their mean age was $71.2 \pm 8.6$ years, sex ratio 77 males $/ 94$ females. The mean duration of cognitive symptoms was 38.3 \pm 28.2 months. Most patients were mildly or moderately demented, as measured by the GDS score (very mildly demented, GDS 3: 17 patients; mildly demented, GDS 4: 77 patients; moderately demented, GDS 5: 55 patients; severely demented, GDS 6: 21 patients). The mean score on the MiniMental State Examination (Folstein et al., 1977) was $18.1 \pm 6.1(2-29)$. The three groups (AD, VD and others) differed with regard to age (70.7, 74.0 and 68.0 years respectively, $p<.05$ ) and the degree of dementia (average GDS scores 4.4, 4.7 and 4.1 respectively, Wilcoxon chi-square:11.3, $\mathrm{d} f=2$, $p<0.05$ ).

In order to assess interobserver reliability, awareness was scored independently by two clinicians (a neuropsychiatrist and a neuropsychologist) in a subgroup of 20 consecutive patients. The kappa value was 0.70 , indicating substantial interobserver agreement (Landis and Koch, 1977).

Lack of insight was a common phenomenon in this population. Of the 170 patients, only $12(7 \%)$ were able to give their history spontaneously without there being clear discrepancies between their 
Table 1. Distribution of awareness scores by severity of cognitive decline (GDS score) among 170 patients with dementia

\begin{tabular}{lccccc}
\hline GDS stage & \multicolumn{4}{c}{ Awareness score } & Total \\
& $\begin{array}{c}4 \\
\text { Intact }\end{array}$ & $\begin{array}{c}\text { Mildly } \\
\text { disturbed }\end{array}$ & $\begin{array}{c}\text { Moderately } \\
\text { disturbed }\end{array}$ & $\begin{array}{c}\text { Severely } \\
\text { disturbed }\end{array}$ & Tur \\
\hline Very mild dementia & $5(29 \%)$ & $11(65 \%)$ & $1(6 \%)$ & $-(0 \%)$ & $17(100 \%)$ \\
4 Mild dementia & $5(7 \%)$ & $45(58 \%)$ & $17(22 \%)$ & $10(13 \%)$ & $77(100 \%)$ \\
5 Moderate dementia & $2(4 \%)$ & $16(29 \%)$ & $30(55 \%)$ & $7(13 \%)$ & $55(100 \%)$ \\
6 Severe dementia & $-(0 \%)$ & $1(5 \%)$ & $7(33 \%)$ & $13(62 \%)$ & $21(100 \%)$ \\
\hline
\end{tabular}

histories and that given by the caregiver. On the other hand, only 30 patients $(18 \%)$ showed a complete lack of insight. Patients with $\mathrm{AD}$ tended to have somewhat higher awareness scores than patients with VD, but this difference was not statistically significant (Kruskal-Wallis, chi-sq. $=2.62$, $\mathrm{d} f=2$ ).

The awareness scores correlated significantly with age (Spearman rank-order correlations $R \mathrm{~s}$ : -0.33 , with $p<0.0001$ ). The distribution of the awareness scores by the severity of dementia (measured by the GDS) is shown in Table 1. There was a significant negative correlation between the GDS score and the awareness score (Rs: -0.51 , with $p<0.0001$ ). In contrast to what has been found in other studies (Cummings et al., 1987; Fischer et al., 1990), we did not find a clear correlation between the HRSD score and the GDS scores (Rs: 0.11 , NS), ie patients who were mildly demented had similar depression scores to those with severe dementia.

Only 16 out of 169 patients $(9 \%$ ), nine with $A D$, four with VD and three with other causes, fulfilled the DSM-III-R criteria for major depression (missing data: $N=1$ ). The distribution of the awareness scores was not unequal between the patients with depression and those without (Kruskal-Wallis, chi-sq. $=0.05, \mathrm{~d} f=1, \mathrm{NS}$ ). In fact, the majority of the patients with depression (nine out of 16) displayed little or no insight into their cognitive deterioration.

Using rank ANOVA with age and GDS scores as covariate, no significant relationship could be found between the awareness score and the depression score $(F=0.42, \mathrm{~d} f=3$, NS). Spearman rank-order correlation coefficients between the awareness scores and the scores on the HRSD (total and subitems) are shown in Table 2.

The mean score on the HRSD was $9.1 \pm 4.9$ $(0-25)$. No significant correlation could be found
Table 2. Correlation coefficients (Spearman rank order) between awareness scores and scores on the Hamilton Rating Scale of Depression (HRSD) in demented patients $(N=169)$

\begin{tabular}{lcc}
\hline & Mean & Rs \\
\hline HRSD, total score & 9.14 & 0.03 \\
Individual HRSD items & & \\
1 Depressive mood & 1.17 & 0.14 \\
2 Suicidal ideation & 0.05 & 0.04 \\
3 Feeling of guilt & 0.26 & 0.12 \\
4 Insomnia, early & 0.09 & 0.07 \\
5 Insomnia, middle & 0.13 & -0.05 \\
6 Insomnia, late & 0.16 & 0.01 \\
7 Work and activities & 1.99 & -0.19 \\
8 Retardation & 1.03 & -0.09 \\
9 Agitation & 0.71 & -0.04 \\
10 Anxiety, psychic & 1.08 & $0.27 *$ \\
11 Anxiety, somatic & 0.57 & 0.11 \\
12 Gastrointestinal complaints & 0.20 & 0.02 \\
13 Somatic complaints, general & 0.65 & 0.06 \\
14 Genital symptoms & 0.10 & 0.10 \\
15 Hypochondriasis & 0.05 & 0.01 \\
16 Loss of weight & 0.26 & -0.04 \\
17 Psychological insight & 0.53 & -0.05 \\
\hline
\end{tabular}

Note: Spearman-rank order correlation, ${ }^{*} p<0.0001$.

between the total HRSD score and the awareness score (Rs: -0.03 , NS). As shown in this table, only the score on the item 'psychic anxiety' indicated a weak but significant correlation with the awareness scores, ie patients showing a greater degree of insight had higher scores on this subitem $(R s: 0.28, p<0.0001)$.

\section{DISCUSSION}

This study showed that impaired awareness was very common in this sample of demented patients. 
In only $7 \%$ of the patients were there no obvious discrepancies between the history provided by the patient and that of the caregiver. However, it was also noted that about half of the patients spontaneously reported problems with their memory at the opening question, indicating at least some partial knowledge of their impairments. Thus, it seems oversimplified to state that it is not possible for patients with memory disorders to remember that one has forgotten' (Fisher, 1989).

A statistically significant correlation was found between the awareness scores and severity of the dementia syndrome as measured by the GDS score, a finding which is consistent with other reports (Reisberg et al., 1985; Feher et al., 1991). No significant relationship could be demonstrated between the level of awareness and the presence of major depression or the total score on the HRSD. The relationship between awareness and depression in dementia has only been examined previously in one study (Feher et al., 1991), in which also no significant correlation could be found between denial scores and Hamilton depression scores. An additional finding in our study was that the depression scores did not correlate with the severity of the dementia. Therefore, this study cannot provide any support for the view that depression lessens as awareness deteriorates with increasing severity of dementia. A relatively intact awareness was not clearly associated with the development of depressive symptoms in dementia and anosognosia did not protect against depression. A modest but significant correlation could be found between awareness scores and the HRSD subscores on the item 'psychic anxiety' even after a Bonferroni type of adjustment. Although this finding should be considered with caution until further research has been done, it may suggest that feelings of anxiety may be secondary to insight into cognitive decline. This supports the notion that symptoms reflecting an internal psychic state are related to psychological mechanisms (Lazarus et al., 1987). In contrast, major depression in dementia, apparently unrelated to the degree of insight, may be predominantly based on neuropathological or neurochemical abnormalities. The possible implications for the treatment of these complaints, namely a more psychological approach to symptoms of anxiety and an emphasis on biological interventions for the treatment of major depression, should be looked at in further studies.

It could be argued that the absence of a relationship between awareness and depression is due to the fact that impaired awareness pertains to both cognition and depression. In this view, a low score on HRSD items might simply reflect anosognosia for depressive feelings, rather than the absence of these symptoms. However, this does not seem very likely, since one would expect that severity of dementia would have then correlated inversely with the depression scores, which is not the case. Additionally, the applicability of the HRSD as an objective clinical rating scale, in contrast to selfreport measures, has been demonstrated even in advanced dementia (Gottlieb et al., 1988; Ott and Fogel, 1992).

Some limitations in this study have to be considered. It is likely that patients who experience cognitive decline will consent more readily to further evaluation in the Memory Clinic than those without any complaints, and thus some degree of selection bias may have occurred. Furthermore, a four-point rating scale may be too global for the assessment of such a complex phenomenon as awareness of deficits. Systematic investigation of anosognosia has begun only recently, and to date, there is no assessment tool available that provides reliable and valid information with certainty. Finally, the assessment of awareness in this study was based on discrepancies between the patients' and the caregivers' reports and thus depends largely on the reliability of the caregiver. However, caregivers of patients with $\mathrm{AD}$ were recently found to be reliable informants of their relatives' memory deficits (Koss et al., 1993), thus this does not seem an important source of error.

\section{CONCLUSIONS}

Our findings suggest that a relatively intact level of awareness in demented patients is not accompanied by an increase in the prevalence of depression. However, it may lead to some specific depressive symptoms, notably psychic anxiety. More research is needed to confirm the results of this study.

\section{APPENDIX}

\section{Guidelines for the rating of awareness of cognitive deficits}

General instructions

After the clinician has introduced himself, he con- 
centrates on the patient, and the caregiver is requested to refrain from any comment.

The following questions are asked:

Please tell me about the problems you are here for. Why did $\mathrm{Dr}$... send you to this clinic?

When the patient has other complaints not directly related to dementia:

\section{Do you have any other complaints?}

When the patient has no spontaneous complaints about his cognitive functions:

How is your memory functioning? Do you think you have a poor memory?

When the patient denies deficits of memory or other cognitive functions:

So, there are no memory problems at all? Is everything going all right for you?

After these opening questions, the complaints are discussed more extensively in an open interview, in which the clinician tries to get an impression of the degree and the nature of the cognitive symptoms and the patient is asked to provide examples.

Then, the clinician puts the same questions to the caregiver adapted to find out about the patient's functions (eg, 'Why did Dr ... refer your father/ mother/ . . . to this clinic?).

\section{Scoring}

Scoring of awareness is made directly after the interview. Allowance should be made in scoring for cognitive impairments such as paraphasias or concretisms (eg, 'There is a hole in my brain').

4 Adequate: Patient has adequate knowledge of his cognitive deficits. Spontaneous complaints about memory or other cognitive dysfunctions. Gives examples. History of the patient is congruent with the history of the informant.

3 Mildly disturbed: Patient has some knowledge of his cognitive deficits, but with some gaps. Spontaneous complaints about memory. History of the patient shows some discrepancies with the history of the informant.

2 Moderately disturbed: Patient has only vague and passive knowledge of cognitive deficits. No spontaneous complaints, admits to memory deficits only when questioned about them. Obvious discrepancies with the history of the informant.

1 Severely disturbed: Denies any deficits. No com- plaints about memory whatsoever, even after explicit questioning.

\section{REFERENCES}

American Psychiatric Association (1987) Diagnostic and Statistical Manual of Mental Disorders, 3rd edition revised. APA, Washington.

Cummings, J. L. (1992) Depression in Parkinson's disease: A review. Am. J. Psychiat. 149, 443-454.

Cummings, J. L., Miller, B. and Hill, M. A. (1987) Neuropsychiatric aspects of multi-infarct dementia and dementia of the Alzheimer type. Arch. Neurol. 44, 38993.

Feher, E. P., Mahurin, R. K., Inbody, S. B., Crook, T. H. and Pirozzolo, F. J. (1991) Anosognosia in Alzheimer's disease. Neuropsychiat. Neuropsychol. Behav. Neurol. 4, 136-146.

Fischer, P., Simanyi, M. and Danielczyk, W. (1990) Depression in dementia of the Alzheimer type and in multi-infarct dementia. Am. J. Psychiat. 147, 1484 1487.

Fisher, C. M. (1989) Neurological fragments. II Remarks on anosognosia, confabulation, memory, and other topics; and an appendix on self-observation. Neuro$\log y 39,127-132$.

Folstein, M., Folstein, S. and McHugh, P. (1977) 'MiniMental State': A practical method for grading the cognitive state of patients for the clinician. J. Psychiat. Res. 12, 189-198.

Gottlieb, G. L., Gur, R. E. and Gur, R. C. (1988) Reliability of psychiatric scales in patients with dementia of the Alzheimer type. Am. J. Psychiat. 145, 857-860.

Hachinski, V. C. (1983) Differential diagnosis of Alzheimer's disease: Multi-infarct dementia. I Alzheimer's Disease: The Standard Reference (B. Reisberg, Ed.). Free Press, New York.

Hamilton, M. (1960) A rating scale for depression. $J$. Neurol. Neurosurg. Psychiat. 23, 56-62.

Koss, E., Patterson, M. B., Ownby, R., Stuckey, J. C. and Whitehouse, P. J. (1993) Memory evaluation in Alzheimer's disease. Caregivers' appraisals and objective testing. Arch. Neurol. 50, 92-97.

Landis, J. R. and Koch, G. G. (1977) The measurement of observer agreement for categorical data. Biometrics 33, 159-174.

Lazarus, L. W., Newton, N., Cohler, B., Lesser, J. and Schweon, C. (1987) Frequency and presentation of depressive symptoms in patients with primary degenerative dementia. Am. J. Psychiat. 144, 41-45.

McAllister, T. W. and Price, T. R. P. (1982) Severe depressive pseudodementia with and without dementia. Am. J. Psychiat. 139, 626-629.

McGlynn, S. M. and Schachter, D. L. (1989) Unawareness of deficits in neuropsychological syndromes. $J$. Exp. Neuropsychol. 1, 143-205. 
McKhann, G., Drachmann, D., Folstein, M., Katzman, R., Price, D. and Stadlan, E. (1984) Clinical diagnosis of Alzheimer's disease: Report of the NINCDSADRDA workgroup under the auspices of the Department of Health and Human Services Task Force on Alzheimer's Disease. Neurology 34, 939-944.

Ott, B. R. and Fogel, B. S. (1992) Measurement of depression in dementia: Self vs clinician rating. Int. J. Geriatr. Psychiatr. 7, 899-904.

Reisberg, B., Ferris, S., de Leon, M. and Crook, T. (1982) The global deterioration scale for assessment of primary degenerative dementia. Am. J. Psychiat. 139, 11361139.

Reisberg, B., Gordon, B., McCarthy, M., Ferris, S. H and de Leon, M. J. (1985) Insight and denial accompanying progressive cognitive decline in normal aging and Alzheimer's disease. In Geriatric Psychiatry: Ethical and Legal Issues. APA Press, Washington, DC.

Rosen, W. G., Terry, R., Fuld, P. A., Katzman, R. and Peck, A. (1980) Pathological verification of ischemic score in the differentiation of dementias. Ann. Neurol. $7,486-488$

Schachter, D. L. (1990) Towards a cognitive neuropsychology of awareness: Implicit knowledge and anosognosia. J. Clin. Exp. Neuropsychol. 12, 155-178.

Siegel, S. and Castellan, N. J. (1988) Nonparametric sys- tems for the behavioral sciences. In Statistical Series (J. D. Anker, Ed.). McGraw-Hill, New York.

Starkstein, S. E. and Robinson, R. G. (1989) Affective disorders and cerebrovascular disease. Brit. J. Psychiat. 154, 170-182.

Verhey, F. R. J., Jolles, J., Ponds, R. W. H., Rozendaal, N., Plugge, L., Vet, H. C. W. D. et al. (1993) Diagnosing dementia: A comparison between a monodisciplinary and a multidisciplinary approach. $J$, Neuropsychiat. Clin. Neurosci. 5, 78-85.

Verwoerdt, A. (1982) Individual psychotherapy in senile dementia. In Clinical Aspects of Alzheimer Disease and Senile Dementia (N. E. Miller and G. Cohen, Eds). Raven Press, New York.

Wells, C. E. (1977) Dementia: Definition and description. In Dementia (C. E. Wells, Ed.). F.A. Davis, Philadelphia.

Wragg, R. E. and Jeste, D. V. (1989) Overview of depression and psychosis in Alzheimer's disease. Am. J. Psychiat. 146, 577-587.

Zubenko, G. S. and Moossy, J. (1988) Major depression in primary dementia: Clinical and neuropathological correlates. Arch. Neurol. 45, 1182-1186.

Zubenko, G. S., Moossy, J. and Kopp, U. (1990) Neurochemical correlates of major depression in primary dementia. Arch. Neurol. 47, 209-214. 